\title{
Health-promotion needs of youth with a spinal cord injury in South Africa
}

\section{E. Njoki, J. Frantz \& R. Mpofu}

Department of Physiotherapy, University of the Western Cape, Bellville, South Africa Accepted May 2006

\begin{abstract}
Purpose. To determine the health promotion needs through an exploration of healthrelated behaviours and the factors that influence the behaviour of physically disabled youth with spinal cord injury.

Methods. A descriptive and exploratory study that utilized a qualitative approach was carried out among ten participants aged between 15 and 29 years who were purposely selected. Information was obtained from individual face-to-face interviews and a focus-group discussion.

Results. The participants were involved in risky health behaviours including sedentary lifestyles, use of alcohol, tobacco, and drugs. Various factors that influenced their participation in these behaviours were identified including personal struggles with identity and adjustment issues.

Conclusions. The results emphasize that participants were involved in health-risk behaviours, which are associated with development of secondary conditions such as respiratory problems, heart diseases, and stroke. Health-promotion strategies employed for these individuals should address the psychological impact of spinal cord injury (SCI) on the individual as an influence to participation in health risk behaviours.
\end{abstract}

Keywords Health promotion, youth, spinal cord injury, secondary conditions

\section{Introduction}

Spinal-cord injury (SCI), usually caused by trauma, often results in severe lifetime physical disabilities and occurs most frequently in young people [1,2]. Through recent advances in medical science and assistive technologies, these young people's life expectancy has increased [2-4] Research in countries such as Canada, Australia and the USA have shown that youth with physical disabilities including those with a SCI are at significant risk for secondary complications such as, respiratory problems, heart disease, stroke, and emotional disorders [5-7]. These secondary complications may present early or become evident later in their lives resulting in deterioration of their health status, functional capacity, and quality of life [7]. Moreover, many of these secondary problems are related to poor lifestyle habits particularly sedentary lifestyles, smoking, alcohol, and drug use $[5,7,8]$. For instance, in a recent study of health-promotion needs, assessments of young people with disabilities including those with physical disabilities in Canada [5], using a cross-sectional descriptive design, found a high level of substance usage and involvement in sedentary activities among these young people. The authors concluded that community-based health- 
promotion interventions are required to address the health- promotion needs of physically disabled young people in order to prevent the onset of secondary disease processes. Another study of 86 people with long- term spinal cord injuries in the USA [9], found that $69 \%$ of subjects used alcohol or drugs prior to injury and increased their consumption post injury.

Although South Africa has a serious lack of reliable information on the statistics and nature of disability, the Quadriplegic Association of South Africa [10] estimates that every year approximately 500 South Africans sustain a spinal cord injury as a result of trauma often leading to severe lifelong physical disabilities. Many of these injuries occur in young people aged between 15 and 29 years.

However although there has been a heightened interest in research on the health status and other areas of need of able-bodied youth, various authors [11,12] point out that there is a paucity of information generally, on the status of people with disabilities in South Africa. According to Bhagwanjee and Stewart [12], this paucity of reliable information has impacted severely upon the planning and development of services and intervention strategies for people with disabilities, especially youth with disabilities. In this regard, these authors point out that research should be targeted at the high-risk youth group, noting that it would be prudent to conceptualize this vexing and complex issue within a health-promotion framework. The present study therefore, aims to determine health-promotion needs through an exploration of health-related behaviours, and factors that influence the behaviour of physically disabled youth with spinal-cord injury. While there is much behaviour that can be related to health, this study focuses mainly on participation in physical activity and substance usage.

\section{Materials and methods}

The study reported used a qualitative framework to gain a phenomenological understanding of the health-promotion needs of young people with spinal cord injury. Since information providing insight into the perceptions of people with spinal cord injury about their health-promotion needs is limited in South Africa, this approach was advocated. Interviews allowed the actual words of the respondents to reveal their feelings, thoughts and their experiences.

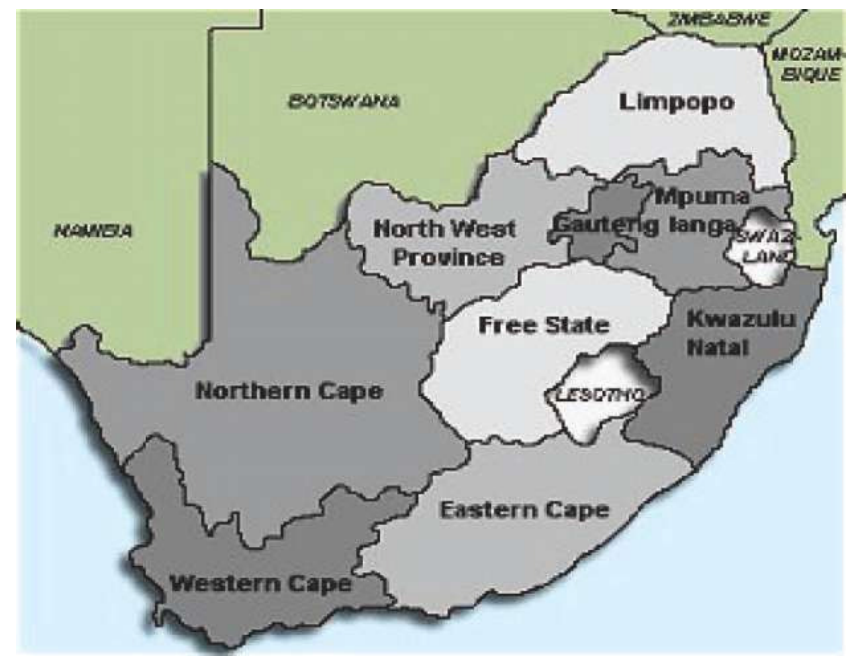


Figure 1. Study participants were recruited through Conradie Hospital Spinal Rehabilitation Unit where patients are referred from hospitals in the area as well as adjacent provinces such as the Northern Province and Eastern Province.

\section{Participants}

Study participants were recruited through Conradie Hospital Spinal Rehabilitation Unit, which is a secondary-level, government-health institution located in Pinelands, Cape Town, and is the biggest spinal rehabilitation unit in South Africa. It serves the whole of the Western Province and patients are referred from hospitals in the area as well as adjacent provinces such as the Northern Province and Eastern Province (Figure 1). Most of the people who sustain a spinal cord injury are aged between 15 and 29 years [10]. Using this guideline for age, inclusion criteria required that participants be youthful aged between 15 and 29 years, English speaking and be physically disabled with a traumatic spinal-cord injury not less than six months post injury. Participants had to have completed their inpatient rehabilitation programmes at the Conradie Hospital Spinal Rehabilitation Unit and had to have been discharged back into the communities within the Western Cape Province. Purposive sampling was used to select potential participants who fitted the inclusion criteria, through the hospital's medical records department. Where a phone number was indicated in the records, these individuals were contacted by phone and those who had no phone addresses were personally visited in their homes or school for an explanation of the study details. Eleven young people living with spinal cord injury were contacted, with ten of them agreeing to participate in the study and only one declining citing lack of free time.

Those who agreed to participate in the study were recruited. The sample contained eight males and two females. Out of the ten participants, eight were again purposively selected for a focus-group interview based on the comments obtained in the interviews. Focus groups allows for a process of sharing and comparing without pressure to reach consensus [19].

\section{Recruitment}

During initial contact, the details of the study were explained to potential participants and if they agreed to participate in the study, an appointment for an interview at mutually acceptable times and locations was made. Participants were asked to agree to a 1-h audiotape interview. At the first interview, informed consent was obtained and parents signed the consent forms of the participants who were under 18 years of age. Participants were informed that they would remain anonymous and when reporting, pseudonyms would be used.

\section{Procedure}

Using a semi-structured interview schedule (see Appendix) informed by existing literature on the subject, face-to-face interviews were conducted with the ten individuals to obtain in-depth descriptions of the participants' health-related behaviours, and the reasons for their engagement in certain behaviours. A focusgroup interview was carried out on completion of the face-to-face interviews. The

\section{https://repository.uwc.ac.za/}


interview was a guided, purposeful conversation, which began with a 'grand tour' question to introduce the general topic of the interview while still allowing each participant to talk about the topic in his or her own way [13].

\section{Focus group discussion}

The focus-group discussion was conducted for about two-and-a-half hours in a convenient, comfortable place and the discussion was audio-recorded to ensure accuracy in data collection. Focus groups create a process of sharing and comparing among the participants [14]. Focus groups have several advantages including: eliciting candid and frank discussions by fostering an open atmosphere; encouraging spontaneous discussion about defined topics: and also people are more likely to selfdisclose or share experiences and feelings in the presence of people whom they perceive to be like them in some way [14,19]. For these reasons, a focus group as a choice of method was utilized to create a dialogue of ideas and points of view that might not have been elicited through individual interviews. One distinctive feature of a focus group is the technique of open- ended questions [14]. The questioning route is a sequence of questions in complete, conversational sentences, for example the first question for the focus group discussion was: "When you hear of healthy living, what comes to mind?"

\section{Data verification}

To ensure credibility of the data, 2 weeks after interviews were completed, transcribed data were presented to five of the participants to validate emergent categories and themes and to confirm the accuracy of the interview transcripts. Transcribed data from the interviews were also peer reviewed by another researcher to do independent coding, and consensus was reached with emerging themes.

\section{Data analysis}

The analysis of the data began with transcription of the interviews. All audio-taped data were transcribed verbatim. Transcriptions were compared to audio- tape recordings to verify accuracy. Each transcript was carefully read through and scrutinized. After reading the transcriptions of interviews several times, analysis of the interview data began with content analysis. Data were coded into broad categories as dictated by the research questions, for example, "what factors have served to influence participants' involvement in certain health-related behaviours?" During the initial category coding, the researcher identified and coded major themes in each interview. Emerging themes were written in the margins of each interview transcription. All the themes were listed and then grouped into categories. Four general themes were established and compared to literature- based concepts.

\section{Results}

Participants ranged in age from 15-21 years, with a mean age of 16.5 years. There were eight male and two female participants. The causes of the injuries in the study

\section{https://repository.uwc.ac.za/}


sample included gunshot wounds $(\mathrm{n}=5)$, diving accidents $(\mathrm{n}=2)$, a rugby injury ( $\mathrm{n}$ $=1)$, fall from a tree $(n=1)$ and a car accident $(n=1)$. Paraplegia was the resulting disability for six youths and quadriplegia for four youths. The time since injury ranged from one year prior to the study to 12 years. Eight out of the ten participants had resumed school after the injury, of which seven were in special schools and one was in a mainstream school. Out of the two participants who had not resumed school, one was staying at home with his father and the other one in a Cheshire home, which is a residential institution for people with disabilities.

The four primary themes that are highlighted in this article include personal influences, perceived needs, support and barriers to positive health related behaviours.

\section{Personal influences}

The theme of personal influences describes participants' statements about their personal struggle with adjustment to a "new identity" after the injury. This process of adjustment negatively or positively influenced their involvement in various healthrelated behaviours. Central to personal influences was the issue of the participants' self-identity, which was linked to their pre-injury identity and the struggle to adjust to a new identity post injury.

Loss of an independent and able identity. This sub- theme encompasses participants' statements about the loss or perceived loss of identity related to their independence and the physical abilities to participate in activities that were significant to them prior to the injury. For instance, Tony (tetraplegia) expressed his struggle with identity by talking about his previous independence.

It is difficult, sometimes you get pressed down emotionally... seeing people walking around you, doing things you used to do ... looking at the television at people doing things and you know you used to do those stuff but now you can't...

Other participants reported missing the activities that had helped define their preinjury identity. For instance, Samson (paraplegia) expressed feelings of frustration at his loss of ability to participate in the sport activity that he was involved in prior to the injury by saying:

It's difficult (long pause) mh... mh it's frustrating coz you know you can't do things that you love to do... like rugby you see, I am crazy about rugby... you see at first I used to feel very frustrated and lonely, you know when I got injured... you see I used to play rugby and I was fit and big... but when I got injured and they (health professionals) explained to me everything ... what I will be able to do and what I won't be able to do and that affected me you know, I won't be able to walk again... means I won't be able play rugby again like before (shakes head)... do all the stuff I like to do ...

For most of the participants in this study, physical activity was connected to their identity prior to the injury. From Nathan and Samson's daily rugby practices to Edwin's frequent swimming and Gideon's daily soccer games with friends, it was 
clear that physical activity played a large role in the daily lives of most of the participants pre-injury. However this changed after the injury. More than half of the participants reported having resorted to sedentary activities such as, watching television, listening to music, sitting and chatting with friends, playing cards and computer games during their leisure time. When asked to describe the sorts of things they did in a day, 'during a typical morning... afternoon... evening', Participants gave responses such as:

... I wake up go and take a bath and go to school... then when I am not in class, I sit and chat with my friends ... when I am at home I do my homework and then listen to the radio or watch TV with my brother... weekends we play computer games with my brother or just watch TV... Edwin (tetraplegia).

Adjusting to a new identity. This sub-theme describes participants' statements about their struggle and strategies used in their attempt to adjust to a new identity. Several participants discussed how they had resorted to behaviours such as the use of tobacco, alcohol, and drugs as a strategy for coping with negative emotions that they experienced. For instance Samson said:

You see I get bored and stressed sometimes ... and smoking (pause) smoking calms the nerves man!... When you are feeling stressed . . . like when I am watching rugby and I see my favourite players and it's like not better than I play it and I say he should have done that and not that... then I light a cigarette ...

Emphasis was put on the use of alcohol, and drug substances as a coping strategy during the focus group discussion, where group support apparently made the participants braver and more nonchalant in reporting their involvement in these substances. For instance Gideon said:

You see Miss, it is difficult . . . you see when you are sitting in the wheelchair sometimes you feel (pause) ... shame for yourself, you know you feel frustrated and just to cool off your mind a couple of beers will help, you won't think so much about the frustrations ...

For other participants, although initially having experienced this struggle with identity, they reported having reached a stage at which they moved on to re-establish a new sense of self. Physical activity was linked to identity for the majority of participants prior to the injury. Similarly, some form of physical activity also appeared to play a role for some participants in the process of adjusting to a new identity, although the actual level and way in which it played a role were different for each person. For instance, Samson stated:

You see at first I used to feel shame for myself all the time, you know you think now I am paralysed and a lot of stuff man! But when I accepted myself the way I am, now I am okay... not to say I don't usually think about those things because I wasn't born in a wheelchair . . . but I never feel that because I won't walk again I shouldn't do things, you know keep myself fit . . . I will do all the things that paraplegics can do ... You see, now I do exercises here in the house, like from my wheelchair to the floor and climbing from the floor to my bed and to the wheelchair and push ups and they are very hard ... 


\section{Perceived needs}

This theme describes the health-related needs as well as other general needs that participants reported as desiring to have or know about.

\section{Health-related needs}

Participants described several factors that inhibited their selection or use of positive health-related behaviours. These factors included, transport problems, lack of facilities and lack of information. Some of these participants expressed a desire to obtain information on health-related behaviours such as exercises, diet, drinking alcohol, smoking, and sexuality. For example, during the focus-group discussion, Tony who was staying in a Cheshire home at the time of the study said:

As for the exercises there are no facilities for exercises here ... they only play dominos there in front ... and another problem we struggle with is transport... because I am interested in doing some exercise ... Yea so I think you need to give us information on how to make our lifestyle more effective like with involvement in sports...

With regard to alcohol, cigarette smoking, and drugs, some participants reported a desire for information on the dangers associated with these substances, and how to quit behaviours such as smoking. For instance during the focus group discussion Samson said:

I am a smoker yea, (laughs) and I don't want to say it's good or bad man! You know I was smoking before my injury and as you know with quitting smoking it is not that easy (pause) maybe you should give me... us information on such stuff man!

Peter, who had chosen to abstain from alcohol, cigarette smoking and drugs, extended his comments beyond his personal experience to observation of others engaging in these substances, with concern saying:

You see some people think drinking (alcohol) and smoking is cool, but it isn't, you see I have seen what these things do to people around here... my neighbours ... in school they talk about some of these things but they should be more specific . . . say more . . . to make people stop using these things ... you see some of my friends in school smoke and drink ...

\section{Other general needs}

Participants presented several views on other areas of need that they felt were essential to them including, employment opportunities, transport issues, and support groups. For example with regard to employment opportunities Nathan said:

I would like any information on job opportunities for disabled people, I dream to become a marketing manager one day now that I am paralysed (pause) I need to know whether it is possible for me to get a job...

As regards transport, some participants felt that the government should put measures in place to have them accommodated within the public modes of transport. For instance Peter said: 
Maybe the government should intervene so that we can have transport that can carry someone in a wheelchair while also carrying normal people, 'cause these things affect people in wheelchairs ... you see because sometimes I feel like I am a prisoner... because these taxi (public vehicles) drivers they speak a lot of nonsense about wheelchairs saying it scratches their seats ...

\section{Support}

Beyond the personal level, the study revealed that there is a second tier of individuals who can have a sizeable impact on the health-related behaviours that youth living with a spinal cord injury choose to engage in. These include family, friends or other people living with spinal cord injury. The participants reported that support offered by family and friends was an important resource when coping with stress and emotional difficulties. Nathan said initially he had resorted to drugs in order to cope with the depression he felt once he got home after his injury. However, he later stopped with the encouragement of his family and friends.

With regard to support groups, many participants felt that forming a support group would be the best strategy for discussing issues pertaining to them. For example, during the focus-group discussion one participant said:

I think the best way to get the best information, is from spinal cord injury people, because they have experienced that (spinal cord injury)... you know it's better... so I would like information on how we can get together like this (focus group) Samson.

\section{Barriers to positive health-related behaviours}

This theme highlighted factors that inhibited the selection of positive health-related behaviours. Participants highlighted that at times opportunities to positive healthrelated behaviours such as physical activity were created but lack of self-confidence and uncertainty of their own abilities prevented them from participating. In addition, the general insensitivity of people and the negative perceptions they felt people in society had towards them also acted as a barrier. Gideon noted:

... Some people only express sympathy, they don't look pass the wheelchair and see me for who I am. They don't allow you to do things for yourself. ... This does not help your self confidence.

\section{Discussion}

The findings of the study indicate the participants' involvement in risky healthrelated behaviours was influenced by various factors. Although a majority of the participants in this study reported that physical activity was of substantial importance to them prior to the injury, many of them reported having resorted to sedentary leisure activities after the injury. This finding is congruent with other studies that have identified high frequencies of sedentary leisure activities in youths with physical disabilities. For instance in a study of lifestyle health behaviours of 11to 16-year-old youths with physical disabilities [7], it was found that these youths were involved in sedentary leisure activities and did little exercise. Similarly, another 
study [5] of health-promotion needs of young people with physical disabilities reported a high level of sedentary activities.

Considering that exercise and activity are of prime importance in the rehabilitation of individuals with physical disabilities including those with a spinal cord injury, physical inactivity that is persistently evident among these individuals should be of concern to rehabilitation professionals. Participants in this study described a number of factors that influenced their participation or lack of participation in physical activity. Many participants recognized that their own attitudes were deeply affected by their sense of identity and that this often stemmed from the difficult process of adjusting to a "new identity" after the injury. They also highlighted their lack of confidence in their own abilities. This finding indicates a need for individual healthpromotion interventions during rehabilitation focused on helping young people with spinal cord injuries refine and develop their identity after the injury. This might be achieved by making them aware of their abilities and encouraging them to participate in alternative physical activity or sports.

Physiotherapists and other rehabilitation professionals should integrate such interventions into their goals of treatment from the onset of the rehabilitation programme so as to promote an active independent attitude towards healthcare among these individuals [13]. Indeed, given the importance attached to physical activity in the formation of pre-injury identity by some of the participants in this study, such health promotion interventions would be essential to these individuals in the process of adjusting to a new identity. The struggle with a new identity after the injury has been reported in other studies. For instance, in a study exploring the experience of ten individuals following spinal cord injury [18] it was noted that the issues of redefining self-identity and establishing a new identity were a common experience. A recent study [20] exploring the experiences of physical activity through the perspective of individuals with a spinal cord injury, found the issue of selfidentity to be an important factor that influenced participation in physical activity. Other factors identified included transport problems, lack of facilities and lack of information. Other studies have also found these factors to be influencing factors to participation in physical activity [20]. Environmental factors such as problems with accessibility and attitudinal problems from the society were found to be some of the major barriers in physical activity participation in a sample of individuals with spinal cord injury.

Participants in this study talked extensively about their involvement in substance usage including the use of alcohol, drugs and tobacco. Many participants attributed their involvement in substance usage to psychosocial difficulties such as frustration, loneliness and boredom experienced during the difficult process of adjusting to a "new identity". Some of the participants however, desired to get help with quitting smoking and others suggested that information on the dangers of substance usage be taught in school. In a study of individuals with spinal cord injury, most (69\%) of whom reported having increased consumption of alcohol after the injury, $16 \%$ of the

\section{https://repository.uwc.ac.za/}


subjects reported needing treatment for alcohol or drug use [9]. Bearing in mind the potential dangers of tobacco and other substance usage, this finding reflects the participants' lack of access to relevant information.

Rehabilitation programmes have often focused primarily on instructing individuals with spinal cord injuries in the necessary techniques of mobility and activities of daily living sometimes neglecting the broader health needs [18]. Judging from the results of the present study, it is important for rehabilitation professionals, particularly physiotherapists, to broaden their services to include health-promotion interventions in addition to their primary roles of improving functional independence. These health- promotion interventions should incorporate individualized programmes tailored to needs of the youth with spinal cord injury. The needs highlighted in the current study such as coming to terms with a changed identity, psychosocial adjustment, information on activities that youths with spinal cord injuries can participate in safely, and information on the dangers of substance usage could assist rehabilitation professionals when planning to intervene. Other areas of need perceived as essential by participants in this study included employment opportunities, transport issues and support groups. The need for a support group was mentioned by a number of participants especially in the focus group discussion where participants discussed their issues openly as they felt at ease with each other. In a case study of people with physical disabilities [12], the importance of self-led support groups of people with spinal cord injury in self-reliance and group participation was demonstrated. Indeed, as the participants in this study said in their accounts, nobody outside this subgroup of people can claim to know their needs better than them. Rehabilitation professionals need to encompass all these needs in their health-promotion interventions.

\section{Limitations}

Data analysis in this study focused on participants' health-promotion needs with regards to physical activity and substance abuse with no focus on additional things such as diet. The information obtained in the study is by interviews and a focus group discussion and used only ten participants. Although other qualitative studies [18] also only used ten participants, additional responses may have generated additional information. Further research should explore additional health-promotion issues affecting young people with spinal cord injury.

\section{Conclusion}

This study revealed that participants had a number of health-promotion needs mainly resulting from their health-related behaviours and the circumstances of the injury. The findings of this study indicate that participants were involved in healthrisk behaviours, which are associated with development of secondary conditions such as respiratory problems, heart disease, and stroke. Although a majority of participants reported being actively involved in sports prior to the injury, most of them had resorted to sedentary lifestyles after the injury. This, as the participants reported, was

\section{https://repository.uwc.ac.za/}


influenced by various factors such as issues of self-identity, transport problems, lack of facilities and lack of information. As a result of the difficult process of adjusting to a "new identity" after the injury, many participants had resorted to substance usage as a coping strategy. Involvement in these health-risk behaviours indicates susceptibility to secondary conditions in the long term. It is clear that healthpromotion strategies to encourage participation in physical activity and elimination of potentially dangerous substance usage are needed to avoid the long-term consequences of sedentary lifestyles and substance abuse in youth as they make the transition to life with a severe impairment and disability. In addition, there is a need for individual exploration of the interests of young people with spinal cord injuries with respect to promoting physical activity and their ability to participate in physical activity.

\section{Acknowledgements}

The authors would like to thank the VLIR/UWC programme for the funding towards this project.

\section{References}

1. Wood-Dauphinee S, Exner G, SCI Consensus Group. Quality of life in patients with spinal cord injury - basic issues, assessments and recommendations. Restorat Neurol Neurosci 2002;20:135-149.

2. Nesathurai S. The rehabilitation of people with spinal cord injury. Epidemiology of traumatic spinal cord injury in the United States. Massachusetts, USA. Library Congress; 2000.

3. Chase B, Cornille T, English R. Cord injuries. J Rehabil 2000;66:14-22.

4. Hulsebosch C. Recent advances in pathophysiology and treatment of spinal cord injury. The American Physiology Society. Adv Physiol Educ 2002;26:238-256.

5. Hogan A, McLellan L, Bauman A. Health promotion needs of young people with disabilities - a population study. Disabil Rehabil 2000;22:352-357.

6. De Vivo M, Krause J, Lammerste D. Recent trends in mortality and causes of death among persons with spinal cord injury. Arch Phys Med Rehabil 1999;80:1411-1419.

7. Steele C, Kalnins I, Jutai J, Stevens S, Bortolussi J, Biggar W. Lifestyle health behaviours of 11- to 16-year-old youth with physical disabilities. Health Educ Res 1996;11(2):173- 186.

8. Messent P, Cooke C, Long J. Primary and secondary barriers to physically active healthy lifestyle for adults with learning disabilities. Disabil Rehabil 1999;21:409-419.

9. Heinemann A, Doll M, Armstrong K, Schnoll A, Yarknoy G. Substance use and receipt of treatment by persons with long-term spinal cord injuries. Arch Phys Med Rehabil 1991; 72:482-489.

10. Quadriplegic Association of South Africa. Spinal cord injury information \& links, at http://quad.stormnet.co.za/info.htm 2002-3.

\section{https://repository.uwc.ac.za/}


11. David S, Jansen P. Well-being and disability: Self-reports from students at a tertiary institution. Int J Rehabil Res 1999;22:233-236.

12.Bhagwanjee M, Stewart R. Disability research in South Africa: Vision and imperatives for a national coordinated approach. South African J Occupat Ther 1999;29:15-17.

13. Stuifbergen A, Rogers S. Health promotion: An essential component of rehabilitation for persons with chronic disabling conditions. Adv Nursing Sci 1997;19:1-20.

14.De Vos A. Research at grass roots: For the social sciences and human services professions. Pretoria: Van Schaik; 2002.

15. Kosma M, Cardinal B, McCubbin J. Research consortium graduate student award winner: Factors influencing physical activity among adults with physical disabilities. Res Quart Exercise Sport 2003;74:2-3.

16.Rimmer J, Braddock D, Pitetti K. Research on physical activity and disability: An emerging national priority. Med Sci Sports Exercise 1996;28:1366-1372.

17. Cooper R, Quatrano L, Axelson P, Harlan W, Stineman M, Franklin B, Krause J, Bach J, Chambers H, Chao E, Alexander M, Painter P. Research on physical activity and health among people with disabilities: A consensus statement. J Rehabil Res Develop 1999;36:142-154.

18. Carpenter C. The experience of spinal cord injury: The individual's perspective - implications for rehabilitation practice. Phys Ther 1994;74:614-629.

19.Krueger R, Casey M. Focus groups: A practical guide for applied research. Thousand Oaks, California: Sage Publications; 2000.

20.Levins S, Redenbach D, Dyck I. Individual and societal influences on participation in physical activity following spinal cord injury: A qualitative study. Phys Ther 2004;84: 496-510. 


\section{Appendix}

\section{Interview guide}

1. Tell me a little about your spinal cord injury: how it occurred ... where and when.

2. Grand tour question: Tell me what it is like for you to live with a spinal cord injury; how does spinal cord injury affect your life?

I want to gain a general picture of the sorts of things that you do. Could you describe to me what you do during a typical morning . . . typical afternoon ... typical evening?

Further description of things mentioned (e.g., ways of coping).

\section{Probes}

- Further description of/things done, e.g., participation in exercise;

- Social context of activities/things done, e.g., recreational activities, things done with friends, e.g., smoking, alcohol consumption, drug use;

- Are these the same things you do on weekends, or are there more/different things that you do over the weekends?

- Comparison of activities/things done now with the ones done before the spinal cord injury;

- Changes in the way an activity is done/how much an activity is done;

- What are the reasons for doing the things/ activities that you do?

- What are the things that you would like to be doing that you are not doing?

- What are the reasons for you not doing these things?

3. Tell me about your health.

\section{Probes}

If in good health:

- What do you do that you feel contributes towards your health?

If in poor health:

- What do you feel contributed to your ill health?

- If you were to give advice to a person with a spinal cord injury about what can help him her live healthy for longer what would you say?

Things to do and things to avoid:

4. Tell me about your support system . . . any support or information you have received (optional)

\section{Probes}

\section{https://repository.uwc.ac.za/}


- Kind of information/support given;

- Who gave the information/support?

5. Tell me what you think you need most to improve your health?

Probes

Further description of things mentioned Are there any other comments that you would like to make about the things that you do generally or about the topic we have been discussing? 